(2) Open Access Full Text Article

REVIEW

\title{
Improving opioid prescription practices and reducing patient risk in the primary care setting
}

\author{
This article was published in the following Dove Press journal: \\ Journal of Pain Research \\ 10 June 2014 \\ Number of times this article has been viewed
}

\author{
Martin D Cheatle \\ Cody Barker \\ Center for Studies of Addiction, \\ Perelman School of Medicine, \\ University of Pennsylvania, \\ Philadelphia, PA, USA
}

Correspondence: Martin D Cheatle Center for Studies of Addiction, Perelman School of Medicine, University of Pennsylvania 3535 Market Street, 4th Floor, Philadelphia, PA 19104, USA

$\mathrm{Tel}+\mathrm{I} 2157467365$

Fax + I6109884952

Email cheatle@mail.med.upenn.edu

\begin{abstract}
Chronic pain is complex, and the patient suffering from chronic pain frequently experiences concomitant medical and psychiatric disorders, including mood and anxiety disorders, and in some cases substance use disorders. Ideally these patients would be referred to an interdisciplinary pain program staffed by pain medicine, behavioral health, and addiction specialists. In practice, the majority of patients with chronic pain are managed in the primary care setting. The primary care clinician typically has limited time, training, or access to resources to effectively and efficiently evaluate, treat, and monitor these patients, particularly when there is the added potential liability of prescribing opioids. This paper reviews the role of opioids in managing chronic noncancer pain, including efficacy and risk for misuse, abuse, and addiction, and discusses several models employing novel technologies and health delivery systems for risk assessment, intervention, and monitoring of patients receiving opioids in a primary care setting.
\end{abstract}

Keywords: chronic pain, opioids, addiction

\section{Introduction}

Patients with chronic pain tend to be complex, and commonly have multiple medical and psychiatric comorbidities, including mood and anxiety disorders, post-traumatic stress disorder, and substance use disorders (SUDs). For example, several studies have demonstrated that patients with pain are more likely to develop depression than patients without pain. ${ }^{1}$ Another study investigated the prevalence of depression in the pain population based on a Medline database search and discovered that the rate of depression varied based on clinical setting, ranging from $85 \%$ in dental clinics specializing in chronic facial pain, to $52 \%$ in pain clinics, $27 \%$ in primary care clinics, and $18 \%$ in population-based settings. ${ }^{2}$ A telephone survey of a community sample revealed that the prevalence of pain was $21.9 \%$, and that $35 \%$ of these pain patients reported suffering from concomitant depression. ${ }^{3}$ Examination of data from the National Comorbidity Survey $(n=5,877)$ further supports that chronic pain is frequently associated with psychiatric disorders. When compared with the general population, patients with chronic pain had a higher prevalence of depression $(20.2 \%$ versus $9.3 \%)$, any anxiety disorder $(35.1 \%$ versus $18.1 \%)$, and post-traumatic stress disorder (10.7\% versus 3.3\%). ${ }^{4}$ Estimates of abuse, misuse, and addiction in pain patients receiving opioid therapy vary from $4 \%$ to greater than $26 \% .^{5}$

Theoretically, patients with chronic pain are complicated and would be best managed in an interdisciplinary pain clinic with access to pain medicine, behavioral health and addiction specialists. The interdisciplinary pain care model relies upon a team of 
health care providers, each with unique skills that serve as collaborators that share consensus-based treatment decisions and goals. ${ }^{6}$ In the USA, interdisciplinary pain clinics are now the exception rather than the rule, ${ }^{7}$ and the number of board certified pain physicians (approximately 3500), who are primarily interventionists, cannot manage the approximate 100 million patients with chronic pain, ${ }^{8}$ leaving the majority of pain care to be delivered by primary care physicians (PCPs). PCPs typically have limited training, resources or time to effectively evaluate, treat and monitor a complex pain patient, especially in regards to a patient that may be misusing or abusing prescription opioids. ${ }^{9}$ While interdisciplinary pain care is suggested as the most efficacious model there are limited data to support this approach over treatment as usual. Additional randomized controlled trials are necessary to justify this claim and challenge reimbursement for these services.

\section{Role of opioids in pain care: efficacy, adverse effects, and risks}

Opioid analgesics have been a key component of pain management for both cancer and noncancer-related pain disorders, although for the purpose of this paper we will be focusing on chronic noncancer pain (CNCP). While opioids can be effective in alleviating pain, there has been growing concern regarding the efficacy and safety of prescribing opioids long term (longer than 90 days) to patients with $\mathrm{CNCP}$, particularly at high doses. Furlan et $\mathrm{al}^{10}$ performed a literature search for randomized controlled trials of opioids for $\mathrm{CNCP}$ and found 62 studies. Of these, 61 had a duration of less than 16 weeks. The results of this meta-analysis demonstrated that both weak and strong opioids were more effective than placebo for both neuropathic pain (effect size $0.56,95 \%$ confidence interval [CI] 0.38-0.73) and nociceptive pain (effect size $0.60,95 \%$ CI $0.49-0.72$ ). This study suggests that opioids have potential for short-term efficacy. A 2010 Cochran review ${ }^{11}$ identified 26 studies that examined the efficacy of opioids in CNCP lasting longer than 6 months. The majority of these studies were case studies or long-term drug trial continuations. A significant percentage of these patients discontinued opioids due to adverse effects $(22.9 \%$, 95\% CI 15.3-32.8) or insufficient pain relief (10.3\%, 95\% CI 7.6-13.9). There was weak evidence that patients who continued on opioids long-term (longer than 6 months) did experience significant pain relief but it was not clear if function or quality of life was improved. A more recent Cochrane review evaluated studies that compared opioids with placebo or other treatments for chronic low back pain. ${ }^{12}$
The authors concluded that there was very low to moderate quality evidence that opioids provided short-term efficacy for both pain and function in treating chronic low back pain as compared with placebo and the few trials that compared opioids with antidepressants or nonsteroidal anti-inflammatory drugs demonstrated no differences with respect to pain and function. They cautioned that commencing long-term opioid therapy should be done judiciously and only after completing a comprehensive evaluation of potential risk factors for abuse. In summary, there is some evidence of short-term efficacy for opioids in treating $\mathrm{CNCP}$, less convincing support for long-term efficacy, and perhaps a subset of patients who benefit from long-term opioid therapy.

While opioids can be beneficial for a number of pain sufferers, a variety of adverse effects can occur with longterm use. These include constipation, nausea, sedation, hyperalgesia, tolerance, sleep disturbance, hypogonadism, immunosuppression, and risk of falls and fractures, particularly in the elderly. ${ }^{13,14}$

Many of these adverse effects can be mitigated with dose adjustment or addition of other medications, such as testosterone supplements for androgen deficiency and bowel regimens for constipation, etc. Of greater concern is the rising prevalence of opioid misuse, abuse, and fatal overdoses. In 2012, 4.9 million persons aged 12 years or older were current nonmedical users of pain relievers, although there was a reduction in the nonmedical use of Oxycodone hydrochloride-extended release from 2010 to 2012, most likely related to the introduction of an abuse-deterrent Oxycodone hydrochloride-extended release formulation. The largest number by drug class of first time use of illicit drugs by individuals 12 years or older in 2012 was for marijuana ( 2.4 million) followed by nonmedical use of pain relievers ( 1.9 million). ${ }^{15}$ In 2011 there were 488,004 emergency department visits related to nonmedical use of opioids ${ }^{16}$ and 186,986 admissions to treatment facilities for opioid dependence. ${ }^{17}$ The estimated prevalence of prescription opioid misuse, abuse, and addiction in the patients with CNCP ranges from less than $1 \%$ to $40 \%{ }^{5,18-22}$ This wide range is most likely attributable to differences in definitions of addiction, clinic setting, and the difficulty in diagnosing an opioid use disorder in patients receiving opioids. Nonetheless, there is persuasive evidence that the prevalence of opioid abuse is not inconsequential in the CNCP patient population.

The steadily increasing rate of opioid-related fatal poisonings is also an alarming trend. There were 38,329 pharmaceutical-related deaths in 2010 in the USA, and 16,651 of these deaths were related to opioids alone 
or in combination with other drugs, the most common being benzodiazepines. ${ }^{23}$ Risk factors for overdose include high dosing of opioids, prescribing methadone which has a variable half-life, history of aberrant drug-related behavior, co-occurring prescribed benzodiazepines, and recent history of SUD and significant psychiatric comorbidities.

The subset of patients that misuse, abuse, or overdose on prescription opioids is heterogeneous in nature and difficult to predict, particularly in a busy PCP setting.

\section{Guidelines for prescribing opioids in chronic noncancer pain}

In an effort to mitigate the risk and maintain the benefits of opioids, a number of opioid prescribing guidelines for patients with CNCP have been developed. In a recent systematic review of opioid guidelines, ${ }^{24} 13$ protocols met the selection criteria, and of these, two were considered to be of the highest quality. These were the American Pain Society/American Academy of Pain Medicine "Clinical guidelines for the use of chronic opioid therapy in chronic noncancer pain" 25 and the "Canadian guideline for safe and effective use of opioids for chronic non-cancer pain". ${ }^{26}$ The majority of recommendations from all the guidelines were based on expert consensus opinion or observational data. Of the 25 recommendations from the American Pain Society/American Academy of Pain Medicine guidelines, 21 were supported by low-quality evidence and the remaining four recommendations were supported by moderate quality of evidence. The Canadian guideline provided 24 recommendations, of which only three were based on randomized controlled trials. Several of the guidelines suggested that opioid dosing be no greater than 90-200 mg of morphine equivalent, methadone should be prescribed judiciously and after the practitioner has acquired additional training, the risks of fentanyl patches should be acknowledged, the clinician should be cognizant of drug-drug and drug-disease interactions, and that there is some utility in the use of risk assessment tools, treatment agreements, and urine drug testing.

\section{Chronic disease management model in CNCP}

There is growing evidence that when pain becomes chronic, it is no longer a mere symptom of an underlying disease but in fact becomes a chronic disease in itself. ${ }^{27}$ The Institute of Medicine report entitled "Relieving Pain in America: A Blueprint for Transforming Prevention, Care, Education, and Research" emphasized that pain should be considered a disease, not unlike other chronic illnesses such as diabetes, hypertension, congestive heart failure, and chronic obstructive pulmonary disease. ${ }^{28}$ While the vast majority of PCPs have little additional training in pain medicine and are generally uncomfortable about managing pain patients, particularly with opioids, ${ }^{9}$ the bulk of pain care is delivered by $\mathrm{PCPs}^{29}$ who are familiar with the chronic care model developed by Wagner et $\mathrm{a}^{30}$ and Wagner. ${ }^{31}$ This is a heuristic model of chronic disease management that emphasizes the importance of clinical information systems, delivery system design, decision support, self-management, and community resources. Chronic disease management relies upon a process of initial evaluation/risk assessment, intervention, monitoring and, if needed, corrective action.

\section{Initial evaluation/risk assessment}

When treating chronic diseases such as diabetes, hypercholesterolemia, and hypertension, PCPs rely on biomarkers such as glycated hemoglobin, lipid levels, and blood pressure readings to assess risk and monitor response to treatment. Risk assessment is an ongoing process when considering initiating opioid therapy or continuing opioids in patients with CNCP and includes utilization of the clinical interview, risk screening tools, urine drug monitoring, mental health, and sleep disorder screening. Clinicians should be cognizant that most of the risk assessment tools (clinical interview, mental health, sleep disorder, and opioid risk assessment instruments) are typically self-report in nature and thus subject to patient bias. The drug-seeking patient could exaggerate their symptoms or minimize past history in order to gain access to opioids.

\section{Clinical interview}

Completing a comprehensive clinical interview is the first step in risk assessment. This should include a review of the patient's past medical history with a specific focus on conditions that may be important with respect to the effects or metabolism of opioids (history of nausea, constipation, pulmonary disease, sleep apnea) or illnesses that may be indicative of a possible history of a SUD (hepatitis, pancreatitis, gastrointestinal disorders). ${ }^{25}$ Heapy and Kerns ${ }^{32}$ also suggested that a clinical interview include an evaluation of psychological and behavioral factors, such as pain intensity and variations, what relieves and exacerbates pain, the impact of pain on the individual's physical, emotional, and psychosocial function, and the patient's goals for treatment. Commencing or maintaining a patient on opioids must be linked to objective goals which need to be revisited on a regular basis. Goal achievement should be objective and verifiable if possible to mitigate patient bias to maintain 
opioid therapy. If available, query the state prescription drug monitoring program and/or contact past medical providers and obtain past medical records to corroborate the history provided by the patient and assess for signs of aberrant drugrelated behaviors. Use of the prescription drug monitoring program has been demonstrated to aid in reducing opioid misuse/abuse, diversion, and overdose. ${ }^{33}$ Evaluate for evidence of physiological tolerance or hyperalgesia if a patient is on a high dose of opioids. Tolerance is a physiological state of adaptation in which dose escalation is required over time to maintain the therapeutic effect of a drug. Patients on chronic opioid therapy commonly display signs of tolerance, evidenced by a gradual increase in the need for higher dose of opioids. Patients abusing opioids will display a pattern of rapid increase in opioid dose and corresponding aberrant drug-related behavior. ${ }^{34}$ Opioid-induced hyperalgesia is a paradoxical phenomenon seen in patients on high-dose chronic opioid therapy which causes a pronociceptive state leading to increased hypersensitivity to pain. While there have been elegant human and animal experimental models of measuring hyperalgesia, in clinical practice hyperalgesia can be assessed by increasing the dose of the prescribed opioid in patients complaining of high pain intensity on a stable dose of opioids. If the pain increases or is unchanged this may be reflective of hyperalgesia and may require opioid rotation. $^{34}$

Initial risk assessment also consists of performing a pain physical examination that includes vital signs, posture, gait, and display of pain behaviors, neurological and musculoskeletal examination, and obtaining diagnostic studies if indicated. ${ }^{25,35}$ Lastly, obtain a history of current and past substance abuse, because the most predictive risk factor for prescription opioid abuse is a past history of SUD. ${ }^{36}$

For patients receiving chronic opioid therapy, the PCP may want to routinely schedule an office visit devoted only to pain issues. This allows for a targeted physical examination, an assessment of the patient's response to both opioid and nonopioid therapies, a review of any changes in pain, mood and sleep, and a review of pertinent medical records and prescription drug monitoring program data for signs of aberrant drug-related behaviors.

\section{Risk assessment tools}

Risk assessment tools are based on identified aberrant drug-related behaviors suggestive of opioid misuse/abuse to help predict risk for future aberrant drug-related behaviors. Prescreening tools designed to assess risk in patients being considered for opioids include the Opioid Risk Tool, ${ }^{37}$
Screener and Opioid Assessment for Patients with Pain, ${ }^{38}$ Diagnosis, Intractability, Risk, Efficacy, ${ }^{39}$ and the Drug Abuse Screening Test. ${ }^{40}$ Instruments used to monitor signs of misuse/abuse in patients currently prescribed opioids include the Pain Assessment and Documentation Tool, ${ }^{41}$ and the Current Opioid Misuse Measure. ${ }^{42}$ Several factors should be considered when selecting an assessment tool to best meet the needs of the PCP practice (eg, daily volume and support staff). These factors include cost, time needed to complete the assessment, whether it is self-administered or requires administration by a staff member, and the ease of scoring the instrument. Also, there is limited evidence of generalizability or feasibility in clinical settings and there is the potential for patient bias. ${ }^{43}$ Further research is needed.

\section{Urine drug monitoring}

Urine drug monitoring is another component of a comprehensive and ongoing risk assessment strategy. Current guidelines ${ }^{25,26}$ and a number of state medical boards recommend routine urine drug monitoring in patients with CNCP receiving chronic opioid therapy, but the frequency of monitoring is widely debated. A recent expert consensus-based guideline on urine drug monitoring suggested that patients at low risk (based on history and results of a risk assessment tool) should be tested a minimum of once every 6 months and patients at medium-high risk should be tested a minimum of once every 3 months. ${ }^{44}$ If a patient being considered for chronic opioid therapy is at moderate to high risk for opioid misuse/abuse based on the initial clinical interview, it may be advisable to obtain a baseline urine drug test to assess for current illicit drug use or use of nonprescribed opioids, benzodiazepines, and stimulants. Testing all patients at baseline regardless of risk status may be judicious since the current monitoring techniques are not particularly sensitive. This establishes expectations regarding the level of monitoring, and if the urine drug screen is positive for either illicit drugs or nonprescribed agents, this allows for early intervention.

Urine drug monitoring is a core element of risk assessment in pain medicine practices, but is underutilized in primary care. ${ }^{45,46} \mathrm{~A}$ lack of familiarity with the types of tests, discomfort interpreting results, and the absence of a clear course of action in the event of inappropriate results have been postulated as reasons for this low utilization in PCP. ${ }^{47}$ Several resources for PCPs to improve their knowledge base regarding urine drug monitoring include a recently published guideline on urine drug monitoring in $\mathrm{CNCP}^{44}$ and a free continuing medical education course for physicians presented by Johns Hopkins School of Medicine. ${ }^{48}$ Other continuing 
medical education programs may also be available through state medical boards.

\section{Mental health screening}

Patients with chronic pain often develop significant concomitant psychiatric disorders, including depression, generalized anxiety disorder, and post-traumatic stress disorder. ${ }^{1-4}$ Patients may misuse or abuse prescription opioids for their anxiolytic and possible hedonic (antidepressant) properties. Suicidal ideation and behavior are prevalent in the chronic pain population. ${ }^{49}$ Underdiagnosing and undertreating related psychological conditions can contribute to poor quality of life and expose vulnerable patients to heightened risk of opioid misuse/abuse.

There are a variety of validated and reliable mental health screening tools. The Beck Depression Inventory (BDI $)^{50}$ and the Profile of Mood States ${ }^{51}$ are two measures that have been recommended by an expert consensus group on measuring emotional functioning in chronic pain. ${ }^{52}$ The BDI is a 21-question self-report measure of depression severity over the past week. The Profile of Mood States has a full-length version (65 items) and a short length version (35 questions), both comprised of seven scales, three of which are particularly relevant to the pain population, including anger/hostility, depression/dejection, and tension/anxiety. Other mental health screening instruments for depression include the Beck Depression Inventory-Fast Screen for Medical Patients (BDIFSMP), ${ }^{53}$ Zung Self-Rating Depression Scale, ${ }^{54}$ and the Center for Epidemiologic Studies Depression Scale. ${ }^{55}$ The Patient Health Questionnaire (PHQ-9) $)^{56}$ is a self-rating instrument derived from the Primary Care Evaluation of Mental Disorders ${ }^{57}$ and contains nine vegetative signs of depression based on the DSM-IV-TR (Diagnostic and Statistical Manual of Mental Disorders, Fourth Edition, Text Revision). Reliability and validity studies revealed that, in a primary care setting, the PHQ-9 detects depression with a sensitivity of approximately $90 \%$ and a specificity ranging from $77 \%$ to $88 \% .^{56,58,59}$

Examples of measures of anxiety include the Beck Anxiety Inventory ${ }^{60}$ and the State Trait Anxiety Inventory. ${ }^{61}$ Tools designed to assess both depression and anxiety include the Hospital Anxiety and Depression Scale, ${ }^{62}$ Hopkins Symptom Checklist, ${ }^{63}$ and the PHQ- $4 .{ }^{64}$ Factor analysis of a large cohort administered the PHQ-4 revealed that two distinctive factors, ie, depression and anxiety, accounted for $84 \%$ of the total variance, and increasing scores were associated with functional status and health care utilization. ${ }^{64}$ Some of these assessment tools are free (eg, PHQ-9 and PHQ-4) and some are proprietary (eg, BDI and BDIFSMP).

\section{Sleep disorder screening}

Patients with chronic pain frequently experience related sleep disturbance, with estimates of up to $70 \%$ of pain patients noting significant sleep interruption. ${ }^{65-67}$ Independently, CNCP and chronic sleep disturbance can contribute to medical and psychiatric morbidities and diminished quality of life. There is a growing literature showing that pain and sleep have a bidirectional relationship. Clearly, poorly controlled pain can disrupt sleep, and there is evidence that a chronic sleep disorder can alter pain perception. ${ }^{68,69}$ The literature on the effect of opioids on sleep yields contradictory results, with one study demonstrating improvement in sleep quality and efficiency ${ }^{70}$ and several other studies reporting that opioids can cause inhibition of rapid eye movement and nonrapid eye movement phases of sleep. ${ }^{71,72}$ Patients receiving chronic opioid therapy also have a high prevalence of sleep apnea ${ }^{73,74}$ and hypoxemia. ${ }^{75}$ If sleep apnea is suspected, it is important to refer the patient to a sleep specialist for testing, especially if considering opioid therapy.

There are a number of self-reported measures of insomnia. Moul et al provide a review of various self-reported measures of different aspects of sleep disorders (eg, sleep quality, sleep onset, and post sleep evaluation). ${ }^{76} \mathrm{~A}$ commonly employed measure is the Pittsburgh Sleep Quality Index, which is a validated questionnaire developed to measure sleep quality. ${ }^{77}$ It is a seven-item questionnaire evaluating sleep duration, sleep efficiency, sleep latency, sleep disturbance, daytime dysfunction, frequency of sleep medications, and subjective sleep quality. Effectively treating mood and sleep can reduce the risk of opioid misuse/abuse.

\section{Risk stratification and monitoring}

Patients can be stratified based on risk and this stratification can be used to determine the level of care and frequency of monitoring that each patient needs based on their risk. Gourlay et $\mathrm{al}^{78}$ suggested three categories:

1. Low risk, defined as no past or current personal or family history of SUD and no or minimal co-occurring psychiatric disorders, can be managed by a PCP. Level of monitoring would be routine follow-up (eg, every 3 months) unless there is a change in pain, function, or mood, or evidence of misuse

2. Moderate risk, defined as past history of SUD, family history of SUD, and moderate concomitant psychiatric disorders should be comanaged by the PCP and specialists (eg, in behavioral health or addiction medicine). Office visits would be more frequent (eg, monthly), with use of pill counts, urine drug monitoring, and medical record 
audit (doctor shopping, emergency department visits) until risk status improves

3. High risk, defined as a patient actively addicted/abusing opioids/illicit drugs and/or with an unstable major psychiatric disorder, should be referred to an interdisciplinary pain center.

Since there are few interdisciplinary pain programs, if a patient presents actively abusing opioids or illicit drugs or displaying behavior suggestive of an unstable psychiatric disorder, referral should be made immediately to a local chemical dependency program or behavioral health center. While risk stratification makes sense clinically, there is no empirical evidence of its efficacy.

\section{Interventions}

Managing complex pain patients in a primary care setting is extremely challenging. Time and resources are limited and often times there is scant access to specialty pain clinics, addiction services, or behavioral health specialists. Every primary care clinic should develop a list of local chemical dependency and behavioral health providers. Clinicians may also find it necessary to develop officebased and technology-assisted interventions and employ community assets.

\section{Office-based interventions}

\section{Pain and depression}

The stress of poorly controlled pain and experience of cooccurring depression can increase the risk of opioid misuse/ abuse. Kroenke et $\mathrm{al}^{79}$ developed and tested a treatment regimen in a primary care setting consisting of 12 weeks of optimized antidepressant therapy followed by a six-session pain self-management program over 12 weeks and continued therapy for an additional 6 months. The results indicated that the treatment group as compared with a treatment as usual group had a $50 \%$ or greater reduction in depression at 12 months from baseline and a clinically significant improvement in pain and function. Embedding such interventions in the primary care setting by using existing resources is promising. Modules could be established to address other common problems associated with pain, such as sleep disorders, and using a similar approach combining an algorithm for pharmacological management of sleep disorders with a self-study program based on the principles of cognitive behavioral therapy (CBT) for insomnia.

Proactively addressing the treatable comorbidities of pain has the potential to improve quality of life and mitigate risk of opioid misuse/abuse.

\section{Substance use disorders}

If a patient is actively abusing either prescription medications (opioids, benzodiazepines, stimulants) or illicit drugs based on the initial risk assessment or subsequent monitoring, referral to a chemical dependency program should be initiated immediately. The Substance Abuse and Mental Health Services Administration provides a website to help locate these types of services (findtreatment.samsha.gov) in or near your community.

Substance Abuse and Mental Health Services Administration and the Center for Substance Abuse Treatment have also developed the Screening, Brief Intervention and Referral to Treatment (SBIRT) initiative for early detection and treatment of SUDs. SBIRT consists of five components. There is an initial screening (systematic screening as part of normal clinical practice in patients at high risk for abuse), followed by a brief intervention (one or two brief visits based on the principles of motivational interviewing and focusing on behavior change and avoiding/reducing risky behavior), brief treatment (2-6 sessions of CBT or motivational enhancement therapy), referral to treatment (patients identified as having more serious SUDs are referred to specialized diagnostic and treatment services), and integration and coordination of services (in communities where SUD services are fragmented or limited, SBIRT functions to coordinate existing services). SBIRT has been designed to be integrated into existing clinics and utilize community resources (http://www.samhsa.gov/ prevention/sbirt/). SBIRT was evaluated in a large multicenter study $^{80}$ of 459,599 patients who were screened in a variety of clinical settings, eg, PCP or emergency departments. The majority of screened patients that were high-risk were offered some level of treatment (brief intervention, brief treatment, referral to specialized treatment center). Results indicated that, in the patients reporting baseline illicit drug use, the rates of drug use were significantly lower at 6 months after SBIRT. These patients also reported improvement in physical and mental health, employment status, and a decrease in criminal behavior.

\section{Telehealth, telemedicine, and mobile health}

With the advent of the Affordable Care Act there is growing interest in technology-assisted delivery of health care. Telemedicine and telehealth are often used interchangeably. Telehealth, however, is a broader umbrella that includes both clinical and nonclinical operations. Telehealth has been defined by the US Department of Health and Human Services as "the use of electronic information and telecommunication 
technologies to support long-distance clinical healthcare, patient and professional health-related education, public health and health administration" ${ }^{81}$ In the management of CNCP, telehealth has included telemedicine, Internet-based CBT, and more recently smart phone applications.

\section{Telemedicine}

Telemedicine is typically face-to-face video interaction between a clinician and a patient, group of patients, or a specialist consulting with a PCP. It has been used extensively in a variety of medical and mental health problems, ${ }^{82,83}$ including in the area of pain medicine. ${ }^{84,85}$ Typically, it is used in rural populations or populations that have limited access to health care. A recent example of the success of telemedicine was the delivery of treatment for PTSD to veterans of the Afghanistan and Iraq conflicts. ${ }^{86}$

\section{Internet/computer-based CBT for pain and SUDs}

There is credible literature supporting the efficacy of CBT in the treatment of patients with a number of pain disorders. ${ }^{87-95}$ There is also persuasive evidence that CBT can be effective in treating patients with SUDs. ${ }^{96-98}$ Due to access issues, whether it be patients living in a rural community where there is a dearth of behavioral health resources such as trained cognitive behavioral therapists or insurance restrictions, there has been a developing literature on the use of Internet/computer-based CBT for treatment of psychiatric disorders and also pain and SUDs.

This technology has been effective in very complex cases. For example, a study by Kay-Lambkin et $\mathrm{al}^{99}$ examined the use of a computer-based CBT intervention for concomitant depression and problematic alcohol or cannabis use. They discovered that the computer-based CBT intervention was as effective as face-to-face CBT interventions. A recent study by Dear et $\mathrm{al}^{100}$ completed a randomized controlled trial of a clinician-guided, Internet-delivered CBT for patients with chronic pain. The results of their study revealed that the treatment group obtained statistically significant improvements as compared with the control group on levels of disability, anxiety, depression, and average pain ratings, both at the end of treatment and at the 3-month follow-up. The subjects in this study also rated their experience with this type of intervention as very positive. The use of computer-assisted CBT software packages in the primary care setting has great potential.

\section{Smart phone applications}

Another opportunity to extend health care interventions to patients is the development of smart phone-based, self-administered interventions. In the treatment of a very refractory population of patients with alcohol use disorder, there has been an evolution of using Internet-based interventions. One meta-analysis that included nine randomized controlled trials revealed that web-based interventions resulted in moderate alcohol reduction. ${ }^{101}$ It has been postulated that the same type of technology-based interventions for alcohol use disorders can be applied to smart phone applications. ${ }^{102}$ This would allow for 24 hour, 7-day/week access, interactivity, and ongoing modifying or adapting of treatments. It could also be employed to identify location of users and provide real-time connection to local support systems.

The use of smart phone applications in pain medicine is promising, considering the high number of smart phone users and the need for easily accessible, efficacious, and cost-effective interventions. A recent study evaluated a smart phone-based intervention using diaries and therapist feedback in a group of women with generalized pain who had completed an inpatient rehabilitation program. For 4 weeks after completion of the inpatient program, the experimental group maintained daily diaries available to a therapist who provided feedback based on CBT principles. At the completion of the smart phone intervention, when compared with the control group, the experimental group reported significantly less pain catastrophizing, and at 5-month follow-up, the experimental group continued to report less catastrophizing and improved acceptance of pain and functioning. ${ }^{103}$

A recent review outlines the variety of smart phone applications currently available for chronic pain. ${ }^{104}$ Further research and development is required because there is a dearth of rigorous evidence to support efficacy, but it is conceivable that there will be evidence-based smart phone applications available to improve pain coping skills and monitor and reduce modifiable risk factors for opioid misuse/abuse.

\section{Collaborative care models for pain management}

A collaborative care model emphasizes integration of care between the patient, the PCP, and the specialist, with support from a nurse case manager and can also include a behavioral health practitioner, chiropractor, or any combination of providers depending on the needs of the individual patient. Several randomized controlled trials have demonstrated the potential efficacy of collaborative care or systems-based enhancements as being superior to usual primary care for improving depression and encouraging literature regarding a collaborative care model for chronic pain. Kroenke et al ${ }^{105}$ have been investigating clinical 
effectiveness in the Stepped Care to Optimize Pain care Effectiveness (SCOPE) study, which is designed to optimize analgesic management in patients with CNCP managed by a PCP. This involves a stepped care intervention including opioid risk stratification, automated symptom monitoring (interactive voice recorded phone calls or Internet-based), and optimized analgesic management provided by a centralized care management team. This team consists of a nurse case manager and a pain physician working in collaboration with the PCP. Cahana et $\mathrm{al}^{106}$ outlined a patient-centric and cost-effective collaborative pain care model to maximize the benefit of opioids while reducing the risk of misuse/ abuse. Based at the Division of Pain Medicine, University of Washington, a regional telemedicine program known as "Telepain" was developed for chronic pain management and encompassed a number of rural and underserved states. This program utilized web-based teleconferencing to provide PCPs with the ability to consult an interdisciplinary pain team and also allowed for monitoring and feedback from patients. A stepped-care approach was applied to opioid prescribing based on guidelines for best clinical practice. A collaborative care model for CNCP is a novel approach that can provide support for a large number of PCPs and their patients.

\section{Discussion}

Patients suffering from chronic pain conditions tend to have complicated etiologies and significant concomitant medical and psychiatric disorders. Managing $\mathrm{CNCP}$ with opioids can be efficacious for a subset of patients; however, the rate of opioid misuse/abuse, diversion, and opioid-related overdose is not inconsequential.

The Institute of Medicine report "Relieving Pain in America: A Blueprint for Transforming Prevention, Care, Education, and Research" 28 has provided a template for pain care reform, emphasizing that pain is a complex disease requiring an interdisciplinary approach. Current models of pain care include unimodality approaches such as interventional pain medicine and multimodal (interventions and pharmacotherapy), multidisciplinary (care provided by several disciplines, typically not coordinated or having shared treatment goals), and interdisciplinary (collaborative team approach emphasizing consensus-based treatment decisions and goal setting) strategies. Interdisciplinary pain programs are on the decline in the USA, ${ }^{7}$ and after receiving specialty care the majority of patients with CNCP are by default managed by PCPs. PCPs typically have limited access to the resources required to effectively and efficiently evaluate, treat, and monitor the complex pain patient, especially when opioids are prescribed.

The recently enacted Affordable Care $\mathrm{Act}^{107}$ may provide the opportunity to change the way pain care is delivered. The Affordable Care Act encourages the development of the "patient-centered medical home", which is based on the chronic care model for managing chronic diseases. The primary components of the patient-centered medical home include use of a multidisciplinary health care team to prevent the development of predictable health problems (based on risk assessment), provide early intervention when health problems develop, and monitor and manage symptoms and function utilizing electronic health record systems and patient registries. In managing patients with $\mathrm{CNCP}$ receiving chronic opioid therapy, the patient-centered medical home model of care would allow for integration of validated risk assessment tools, novel treatment delivery systems (telemedicine, Internet/ computer-assisted CBT, smart phone apps), and monitoring capability (electronic health record systems, prescription drug monitoring program). Assisting this process, there has also been an effort to embed into the electronic health record system a computerized decision support system based on expert consensus guidelines on chronic opioid therapy for $\mathrm{CNCP}$ to guide decision-making when prescribing opioids. ${ }^{108}$ Results have been promising, but further research is required.

Caring for patients with chronic pain can be challenging, especially when considering initiating or maintaining a patient on opioids. The clinician must balance the ethical obligation of providing effective pain relief but not exposing a vulnerable patient to potential development of an opioid use disorder. Substantial work is required to further develop, rigorously test, and refine evolving models of care and technology-assisted interventions to support the PCP in managing the growing number of patients with CNCP. For new models of pain care to be successful, certain barriers must be addressed. PCPs need to be appropriately reimbursed for managing complex cases that require additional time for comprehensive assessment and monitoring and coordinating care with specialists. Obstacles to PCPs adhering to guidelines and new systems, such as an electronic health record systems-embedded computerized decision support system, must be identified and eliminated. Funds for research and development of novel delivery systems need to be allotted. None of these obstacles are insurmountable, and it is conceivable that advancing and integrating these new approaches into primary care practice will substantially alleviate individual suffering and reduce the risk of opioid abuse and diversion. 


\section{Acknowledgment}

MDC would like to acknowledge the support of grant 1R01DA032776-01 from the National Institute on Drug Abuse, National Institutes of Health in the writing of this paper.

\section{Disclosure}

The authors report no conflicts of interest in this work.

\section{References}

1. Magni G, Marchetti M, Moreschi C, Merskey H, Luchini S. Chronic musculoskeletal pain and depressive symptoms in the National Health and Nutrition Examination, I: epidemiologic follow-up study. Pain. 1993;53(2):163-168.

2. Bair MJ, Robinson RL, Katon W, Kroenke K. Depression and pain comorbidity: a literature review. Arch Intern Med. 2003;163(20): 2433-2445.

3. Miller LR, Cano A. Comorbid chronic pain and depression: who is at risk? J Pain. 2009;10(6):619-627.

4. McWilliams LA, Cox BJ, Enns MW. Mood and anxiety disorders associated with chronic pain: an examination in a nationally representative sample. Pain. 2003;106(1-2):127-133.

5. Fleming MF, Balousek SL, Klessig CL, Mundt MP, Brown DD. Substance use disorders in a primary care sample receiving daily opioid therapy. J Pain. 2007;8(7):573-582.

6. Turk DC, Paice JA, Cowan P, et al. American Pain Society. Interdisciplinary pain management. Available from: http://www. americanpainsociety.org/uploads/pdfs/2010Interdisciplinary WhitePaper-FINAL.pdf. Accessed March 1, 2014.

7. Schatman ME. Interdisciplinary chronic pain management: international perspectives. ISAP Pain Clinical Updates. 2012;XX(7): $1-5$.

8. Tsang A, Von Korff M, Lee S, et al. Common chronic pain conditions in developed and developing countries: gender and age differences and comorbidity with depression-anxiety disorders. J Pain. 2008;9(10): 883-891.

9. Upshur CC, Luckmann RS, Savageau JA. Primary care provider concerns about management of chronic pain in community clinic populations. J Gen Intern Med. 2006;21(6):652-655.

10. Furlan AD, Chaparro LE, Irvin E, Mailis-Gagnon A. A comparison between enriched and nonenriched enrollment randomized withdrawal trials of opioids for chronic noncancer pain. Pain Res Manage. 2011;16(5):337-351.

11. Noble M, Treadwell JR, Tregear SJ, et al. Long-term opioid management for chronic noncancer pain. Cochrane Database Syst Rev. 2010;1:CD006605.

12. Chaparro LE, Furlan AD, Deshpande A, Mailis-Gagnon A, Atlas S, Turk DC. Opioids compared to placebo or other treatments for chronic low-back pain. Cochrane Database Syst Rev. 2013;8:CD004959.

13. Brown RT, Zuelsdorff M, Fleming M. Adverse effects and cognitive function among primary care patients taking opioids for chronic nonmalignant pain. J Opioid Manag. 2006;2(3):137-146.

14. Cheatle MD, Savage SR. Informed consent in opioid therapy: a potential obligation and opportunity. J Pain Symptom Manage. 2012;44(1):105-116

15. Substance Abuse and Mental Health Services Administration. Results from the 2012 National Survey on Drug Use and Health: Summary of National Findings. NSDUH Series H-46, HHS Publication No (SMA) 13-4795. Rockville, MD, USA: Substance Abuse and Mental Health Services Administration; 2013. Available from: http:// www.samhsa.gov/data/NSDUH/2012SummNatFindDetTables/ NationalFindings/NSDUHresults2012.pdf. Accessed May 2, 2014.
16. Substance Abuse and Mental Health Services Administration, Drug Abuse Warning Network, 2011. National Estimates of Drug-Related Emergency Department Visits. HHS Publication No (SMA) 13-4760, DAWN Series D-39. Rockville, MD, USA: Substance Abuse and Mental Health Services Administration; 2013. Available from: http:// www.samhsa.gov/data/2k13/DAWN2k11ED/DAWN2k11ED.htm. Accessed May 2, 2014.

17. Substance Abuse and Mental Health Services Administration, Center for Behavioral Health Statistics and Quality. Treatment Episode Data Set (TEDS): 2001-2011. National Admissions to Substance Abuse Treatment Services. BHSIS Series S-65, HHS Publication No (SMA) 13-4772. Rockville, MD, USA: Substance Abuse and Mental Health Services Administration; 2013. Available from: http://www.samhsa. gov/data/2k13/TEDS2011/TEDS2011N.pdf. Accessed May 2, 2014.

18. Reid MC, Engles-Horton LL, Weber MB, Kerns RD, Rogers EL, O'Connor PG. Use of opioid medications for chronic noncancer pain syndromes in primary care. J Gen Intern Med. 2002;17(3):173-179.

19. Katz N, Sherburne S, Beach M, et al. Behavioral monitoring and urine toxicology testing in patients receiving long-term opioid therapy. Anesth Analg. 2003;97(4):1097-1102.

20. Ives TJ, Chelminski PR, Hammett-Stabler CA, et al. Predictors of opioid misuse in patients with chronic pain: a prospective cohort study. $B M C$ Health Serv Res. 2006;6:46.

21. Martell BA, O’Connor PG, Kerns RD, et al. Systematic review: opioid treatment for chronic back pain: prevalence, efficacy, and association with addiction. Ann Intern Med. 2007;146(2):116-127.

22. Fishbain DA, Cole B, Lewis J, Rosomoff HL, Rosomoff RS. What percentage of chronic nonmalignant pain patients exposed to chronic opioid analgesic therapy develop abuse/addiction and/or aberrant drug-related behaviors? A structured evidence-based review. Pain Med. 2008;9(4):444-459.

23. Jones CM, Mack KA, Paulozzi LJ. Pharmaceutical overdose deaths, United States, 2010. JAMA. 2013;309(7):657-659.

24. Nuckols TK, Anderson L, Popescu I, et al. Opioid prescribing: a systematic review and critical appraisal of guidelines for chronic pain. Ann Intern Med. 2014;160(1):38-47.

25. Chou R, Fanciullo GJ, Fine PG, et al. Clinical guidelines for the use of chronic opioid therapy in chronic noncancer pain. J Pain. 2009;10(2):113-130.

26. National Opioid Use Guideline Group Canadian guideline for safe and effective use of opioids for chronic non-cancer pain. Hamilton, ON, Canada: McMaster University; 2010. Available from: http:// nationalpaincentre.mcmaster.ca/opioid/cgop_a00_executive_summary. html. Accessed November 18, 2013.

27. Tracey I, Bushnell MC. How neuroimaging studies have challenged us to rethink: is chronic pain a disease? J Pain. 2009;10(11):1113-1120.

28. Institute of Medicine. Relieving Pain in America: A Blueprint for Transforming Prevention, Care, Education, and Research. Washington, DC, USA: The National Academies Press; 2011.

29. Breuer B, Cruciani R, Portenoy RK. Pain management by primary care physicians, pain physicians, chiropractors, and acupuncturists: a national survey. South Med J. 2010;103(8):738-747.

30. Wagner EH, Austin BT, Von Korff M. Improving outcomes in chronic illness. Manag Care Q. 1996;4(2):12-25.

31. Wagner EH. Chronic disease management: what will it take to improve care for chronic illness? Eff Clin Pract. 1998;1(1):2-4.

32. Heapy A, Kerns RD. Psychological and behavioral assessment. In: Benzon HT, Rathmel JP, Wu CL, Turk DC, Argoff CE, editors. Raj's Practical Management of Pain. 4th ed. Philadelphia, PA, USA: Mosby/ Elsevier; 2008.

33. Morgan L, Weaver M, Sayeed Z, Orr R. The use of prescription monitoring programs to reduce opioid diversion and improve patient safety. J Pain Palliat Care Pharmacother. 2013;27(1):4-9.

34. Cheatle MD, O'Brien CP. Opioid therapy in patients with chronic noncancer pain: diagnostic and clinical challenges. Adv Psychosom Med. 2011;30:61-91. 
35. Lalani I, Argoff CE. History and physical examination of the pain patient. In: Benzon HT, Rathmel JP, Wu CL, Turk DC, Argoff CE, editors. Raj's Practical Management of Pain. 4th ed. Philadelphia, PA, USA: Mosby/Elsevier; 2008.

36. Turk DC, Swanson KS, Gatchel RJ. Predicting opioid misuse by chronic pain patients: a systematic review and literature synthesis. Clin J Pain. 2008;24(6):497-508.

37. Webster LR, Webster RM. Predicting aberrant behaviors in opioidtreated patients: preliminary validation of the Opioid Risk Tool. Pain Med. 2005;6:432-442.

38. Butler S, Budman S, Fernandez K, Jamison RN. Validation of a screener and opioid assessment measure for patients with chronic pain. Pain. 2004;112(1-2):65-75.

39. Belgrade M, Schamber C, Lindgren B. The DIRE score: predicting outcomes of opioid prescribing for chronic pain. J Pain. 2006;7(9):671-681.

40. Skinner HA. The drug abuse screening test. Addict Behav. 1982;7(4): 363-371.

41. Passik S, Kirsh KL, Whitcomb L, et al. A new tool to assess and document pain outcomes in chronic pain patients receiving opioid therapy. Clin Ther. 2004;26(4):552-561.

42. Butler S, Budman SH, Fernandez KC, et al. Development and validation of the Current Opioid Misuse Measure. Pain. 2007;130(1-2):144-156.

43. Becker WC, Fraenkel L, Edelman EJ, Holt SR, Glover J, Kerns RD, Fiellin DA. Instruments to assess patient-reported safety, efficacy, or misuse of current opioid therapy for chronic pain: a systematic review. Pain. 2013;154(6):905-916.

44. Peppin JF, Passik SD, Couto JE, et al. Recommendations for urine drug monitoring as a component of opioid therapy in the treatment of chronic pain. Pain Med. 2012;134(7):886-896.

45. Bhamb B, Brown D, Hariharan J, et al. Survey of select practice behaviors by primary care physicians on the use of opioids for chronic pain. Curr Med Res Opin. 2006;22(9):1859-1865.

46. Boulanger A, Clark AJ, Squire P, Cui E, Horbay GL. Chronic pain in Canada: have we improved our management of chronic noncancer pain? Pain Res Manag. 2007;12(1):39-47.

47. Reisfield GM, Graham NA, Gold MS. Urine drug testing is still an invaluable resource for primary care. Ann Intern Med. 2010;153(6):420.

48. Gourlay D, Heit H, Caplan Y. Urine drug testing in clinical practice: the art and science of patient care. 5th ed. Available from: http://www. pharmacomgroup.com/udt/udt5.pdf. Accessed December 1, 2013.

49. Cheatle MD. Depression, chronic pain, and suicide by overdose: on the edge. Pain Med. 2011;12 Suppl 2:S43-S48.

50. Beck A, Ward C, Mendelson M, Mock J, Erbaugh J. An inventory for measuring depression. Arch Gen Psychiatry. 1961;4:561-571.

51. McNair D, Lorr M, Droppleman L. Profile of Mood States. San Diego, CA, USA: Educational and Industrial Testing Service; 1971.

52. Dworkin R, Turk DC, Farrar JT, et al. IMMPACT. Core outcome measures for chronic pain trials: IMMPACT recommendations. Pain. 2005;113(1-2):9-19.

53. Beck A, Steer R, Brown C. Beck Depression Inventory-Fast Screen for Medical Patients Manual. San Antonio, TX, USA: Psychological Corporation; 2000.

54. Zung W. A self-rating depression scale. Arch Gen Psychiatry. 1965;12:63-70.

55. Radloff L. The CES-D scale: a self-report depression scale for research in the general population. Appl Psychol Meas. 1977;1:385-401.

56. Kroenke K, Spitzer RL, Williams JB. The PHQ-9: validity of a brief depression severity measure. J Gen Intern Med. 2001;16(9):606-613.

57. Spitzer RL, Williams JB, Kroenke K, et al. Utility of a new procedure for diagnosing mental disorders in primary care. The PRIME-MD 1000 study. JAMA. 1994;272(22):1749-1756.

58. Gilbody S, Richards D, Brealey S, Hewitt C. Screening for depression in medical settings with the Patient Health Questionnaire (PHQ): a diagnostic metaanalysis. J Gen Intern Med. 2007;22(11):1596-1602.

59. Lowe B, Grafe K, Zipfel S, et al. Diagnosing ICD-10 depressive episodes: superior criterion validity of the patient health questionnaire. Psychother Psychosom. 2004;73(6):386-390.
60. Beck AT, Epstein N, Brown G, Steer RA. An inventory for measuring clinical anxiety: psychometric properties. J Consult Clin Psychol. 1988;56(6):893-897.

61. Spielberg C, Gorsuch R, Lushene R. Manual for the State-Trait Anxiety Inventory. Palo Alto, CA, USA: Consulting Psychologists; 1970.

62. Bjelland L, Dahl AA, Haug TT, Neckelmann D. The validity of the Hospital Anxiety and Depression Scale. An updated literature review. J Psychosom Res. 2002;52(2):69-77.

63. Derogatis LR, Lipman RS, Rickels K, Uhlenhuth EH, Covi L. The Hopkins Symptom Checklist (HSCL): a self-report symptom inventory. Behav Sci. 1974;19(1):1-15.

64. Kroenke K, Spitzer RL, Williams JB, Lowe B. An ultrabrief screening scale for anxiety and depression: the PHQ-4. Psychosomatics. 2009;50(6):613-621.

65. Atkinson JH, Ancoli-Israel S, Slater M, et al. Subjective sleep disturbance in chronic pain. Clin J Pain. 1988;4:225-232.

66. Morin C, Gibson D, Wade J. Self-reported sleep and mood disturbance in chronic pain patients. Clin J Pain. 1998;14:311-314.

67. Allen KD, Renner JB, DeVellis B, Helmick C, Jordan JM. Osteoarthritis and sleep: the Johnston County Osteoarthritis Project. $J$ Rheumatol. 2008;35(6):1102-1107.

68. Moldofsky H. Sleep and pain. Sleep Med Rev. 2001;5(5):385-396.

69. Smith MT, Haythornthwaite JA. How do sleep disturbance and chronic pain inter-relate? Insights from the longitudinal and cognitive-behavioral clinical trials literature. Sleep Med Rev. 2004;8(2):119-132.

70. Brennan MJ, Lieberman JA. Sleep disturbances in patients with chronic pain: effectively managing opioid analgesia to improve outcomes. Curr Med Res Opin. 2009;25(5):1045-1055.

71. Shaw IR, Lavigne G, Mayer P, Choiniere M. Acute intravenous administration of morphine perturbs sleep architecture in healthy pain-free young adults: a preliminary study. Sleep. 2005;28(6):677-682.

72. Rosenberg J. Sleep disturbances after non-cardiac surgery. Sleep Med Rev. 2001;5(2):129-137.

73. Webster LR, Choi Y, Desai H, Webster L, Grant BJ. Sleep-disordered breathing and chronic opioid therapy. Pain Med. 2008;9(4): 425-432.

74. Walker JM, Farney RJ. Are opioids associated with sleep apnea? A review of the evidence. Curr Pain Headache Rep. 2009;13(2):120-126.

75. Mogri M, Desai H, Webster L, Grant BJ, Mador MJ. Hypoxemia in patients on chronic opiate therapy with and without sleep apnea. Sleep Breath. 2009;13(1):49-57.

76. Moul DE, Hall M, Pilkonis PA, Buysse DJ. Self-report measures of insomnia in adults: rationales, choices, and needs. Sleep Med Rev. 2004;8(3):177-198.

77. Buysse DJ, Reynolds CF 3rd, Monk TH, Berman SR, Kupfer DJ. The Pittsburgh Sleep Quality Index: a new instrument for psychiatric practice and research. Psychiatry Res. 1989;28(2):193-213.

78. Gourlay DL, Heit HA, Almahrezi A. Universal precautions in pain medicine: a rational approach to the treatment of chronic pain. Pain Med. 2005;6(2):107-112.

79. Kroenke K, Bair MJ, Damush TM, et al. Optimized antidepressant therapy and pain self-management in primary care patients with depression and musculoskeletal pain: a randomized controlled trial. JAMA. 2009;301(20):2099-2110

80. Madras BK, Compton WM, Avula D, Stegbauer T, Stein JB, Clark HW. Screening, brief interventions, referral to treatment (SBIRT) for illicit drug and alcohol use at multiple healthcare sites: comparison at intake and 6 months later. Drug Alcohol Depend. 2009;99(1-3): 280-295.

81. US Department of Health and Human Services, Health Resources and Services Administration. Results from the 2012 National Survey on Drug Use and Health: Summary of National Findings. Available from: http://www.hrsa.gov/ruralhealth/about/telehealth/. Accessed January 14, 2014.

82. Liss HJ, Glueckauf RJ, Ecklund-Johnson EP. Research on telehealth and chronic medical conditions: critical review, key issues, and future directions. Rehabil Psychol. 2002;47(1):8-30. 
83. Cuijpers P, Marks IM, van Straten A, Cavanagh K, Gega L, Andersson G. Computer-aided psychotherapy for anxiety disorders: a meta-analytic review. Cogn Behav Ther. 2009;38(2):66-82.

84. Keogh E, Rosser BA, Eccleston C. e-health and chronic pain management: current status and developments. Pain. 2010;151(1):18-21.

85. Sato AF, Clifford LM, Silverman AH, Davies W. Cognitive-behavioral interventions via telehealth: applications to pediatric functional abdominal pain. Child Health Care. 2009;38(1):1-22.

86. Tuerk PW, Yoder M, Ruggiero K, Gros DF, Acierno R. A pilot study of prolonged exposure therapy for posttraumatic stress disorder delivered via telehealth technology. J Trauma Stress. 2010;23(1):116-123.

87. Manchikanti L. CBT for low-back pain in primary care. Lancet. 2010;375(9718):869-870.

88. Lamb SE, Hansen Z, Lall R, Castelnuovo E, Withers EJ, Nichols V. Group cognitive behavioural treatment for low-back pain in primary care: a randomized controlled trial and cost-effectiveness analysis. Lancet. 2010;375(9718):916-923.

89. Thieme K, Flor H, Turk D. Psychological pain treatment in fibromyalgia syndrome: efficacy of operant behavioral and cognitive behavioral treatments. Arthritis Res Ther. 2006;8(4):R121.

90. Linton SJ. A 5-year follow-up evaluation of the health and economic consequences of an early cognitive behavioral intervention for back pain: a randomized, controlled trial. Spine. 2006;31(8):853-858.

91. Keefe FJ, Caldwell DS. Cognitive behavioral control of arthritis pain. Med Clin North Am. 1997;81(1):277-290.

92. Chen E, Cole SW, Kato PM. A review of empirically supported psychosocial interventions for pain and adherence outcomes in sickle cell disease. J Pediatr Psychol. 2004;29(3):1997-2009.

93. Glombiewski JA, Hartwich-Tersek J, Rief W. Two psychological interventions are effective in severely disabled, chronic back pain patients: a randomized controlled trial. Int J Behav Med. 2010;17(2):97-107.

94. Turner JA, Manci L, Aaron LA. Short- and long-term efficacy of brief cognitive-behavioral therapy for patients with chronic temporomandibular disorder pain: a randomized, controlled trial. Pain. 2006;121(3):181-194.

95. Greco CM, Rudy TE, Manzi S. Effects of a stress-reduction program on psychological function, pain, and physical function of systemic lupus erythematosus patients: a randomized controlled trial. Arthritis Rheum. 2004;51(4):625-634.

96. Holder HD, Cisler R, Longabaugh R, Stout RL, Treno AJ, Zweben A. Alcoholism treatment and medical care costs from Project MATCH. Addiction. 2000;95(7):999-1013.
97. Dutra L, Stathopoulou G, Basden SL, Leyro TM, Powers MB, Otto MW. A meta-analytic review of psychosocial interventions for substance use disorders. Am J Psychiatry. 2008;165(2):179-187.

98. Osilla KC, Hepner KA, Muñoz RF, Woo S, Watkins K. Developing an integrated treatment for substance use and depression using cognitivebehavioral therapy. J Subst Abuse Treat. 2009;37(4):412-420.

99. Kay-Lambkin FJ, Baker AL, Lewin T, Carr VJ. Computer-based psychological treatment for comorbid depression and problematic alcohol and/or cannabis use: a randomized controlled trial of clinical efficacy. Addiction. 2009;104(3):378-388.

100. Dear BF, Titov N, Perry KN, et al. The Pain Course: a randomised controlled trial of a clinician-guided Internet-delivered cognitive behaviour therapy program for managing chronic pain and emotional well-being. Pain. 2013;154(6):942-950.

101. Riper H, Spek V, Boon B, et al. Effectiveness of E-self-help interventions for curbing adult problem drinking: a meta-analysis. $\mathrm{J} \mathrm{Med}$ Internet Res. 2011;13(2):e42.

102. Dulin PL, Gonzalez VM, King DK, Giroux D, Bacon S. Smartphonebased, self-administered intervention system for alcohol use disorders: theory and empirical evidence basis. Alcohol Treat Q. 2013;31(3).

103. Kristjánsdóttir OB, Fors EA, Eide E, et al. A smartphone-based intervention with diaries and therapist-feedback to reduce catastrophizing and increase functioning in women with chronic widespread pain: randomized controlled trial. J Med Internet Res. 2013;15(1):e72.

104. Wallace LS, Dhingra LK. A systematic review of smartphone applications for chronic pain available for download in the United States. J Opioid Manag. 2014;10(1):63-68.

105. Kroenke K, Krebs E, Wu J, et al. Stepped Care to Optimize Pain care Effectiveness (SCOPE) trial study design and sample characteristics. Contemp Clin Trials. 2013;34(2):270-281.

106. Cahana A, Dansie EJ, Theodore BR, Wilson HD, Turk DC. Redesigning delivery of opioids to optimize pain management, improve outcomes, and contain costs. Pain Med. 2013;14(1):36-42.

107. Patient Protection and Affordable Care Act. Public Law No: 111-148: HR 3590. March 23, 2010.

108. Trafton JA, Martins SB, Michel MC, et al. Designing an automated clinical decision support system to match clinical practice guidelines for opioid therapy for chronic pain. Implement Sci. 2010;5:26.
Journal of Pain Research

\section{Publish your work in this journal}

The Journal of Pain Research is an international, peer-reviewed, open access, online journal that welcomes laboratory and clinical findings in the fields of pain research and the prevention and management of pain. Original research, reviews, symposium reports, hypothesis formation and commentaries are all considered for publication.

\section{Dovepress}

The manuscript management system is completely online and includes a very quick and fair peer-review system, which is all easy to use. Visit http://www.dovepress.com/testimonials.php to read real quotes from published authors. 